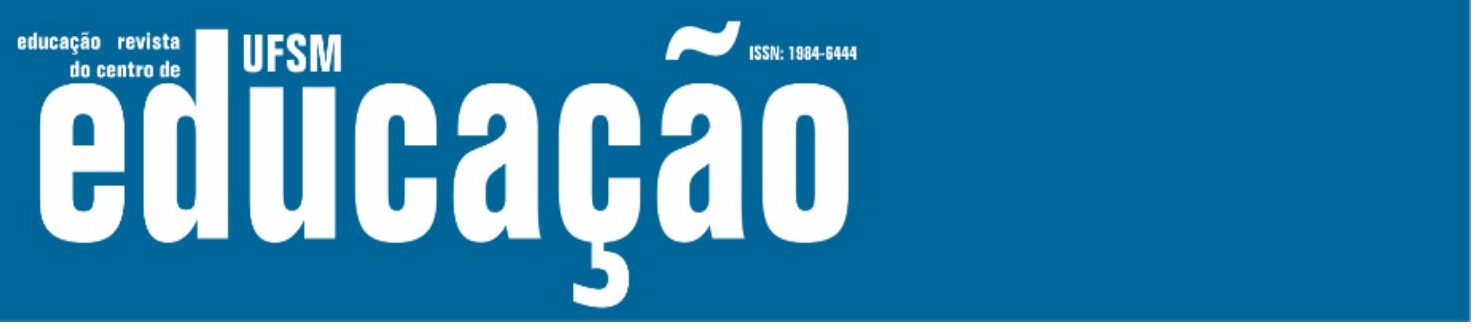

ISSN: 1984-6444 | http://dx.doi.org/10.5902/1984644438552

\title{
O ensino de estratégias de aprendizagem por integração curricular na disciplina de biologia: uma experiência pedagógica
}

The teaching of learning strategies by curricular integration in the discipline of biology: a pedagogical experience

La enseñanza de estrategias de aprendizaje por integración curricular en la asignatura de biologia: una experiencia pedagógica

Deivid Alex dos Santos

Doutorando na Universidade Estadual de Londrina. Londrina, Paraná, Brasil. mensagemprodeivid@gmail.com - https://orcid.org/0000-0002-2611-6947

Paula Mariza Zedu Alliprandini

Professora doutora na Universidade Estadual de Londrina. Londrina, Paraná, Brasil. paulaalliprandini@uel.br - http://orcid.org/0000-0003-4677-4258

Recebido em 21 de janeiro de 2020

Aprovado em 19 de fevereiro de 2020

Publicado em 21 de dezembro de 2020

\section{RESUMO}

Este trabalho relata a experiência de uma intervenção por integração curricular, realizada por meio do ensino de estratégias de aprendizagem, envolvendo 26 alunos que cursavam a disciplina de Biologia no $3^{\circ}$ ano do Ensino Médio. Esta intervenção é caracterizada como um método em que o professor pode inserir o ensino de estratégias de aprendizagem junto ao conteúdo de sua disciplina, aliada à estrutura curricular. Com a duração de um semestre letivo, o processo de intervenção compreendeu 36 horas/aulas dispostas em 13 sessões interventivas, organizadas de acordo com o conteúdo a ser ministrado. Foi priorizado o ensino de estratégias de aprendizagem cognitivas devido aos resultados obtidos após a aplicação de uma escala em estratégias de aprendizagem. Após a realização da experiência, observouse uma mudança positiva no comportamento dos alunos frente às atividades de aprendizagem e foi constatada a importância do domínio dos conteúdos e dos saberes inerentes às estratégias de aprendizagem e a possibilidade de inclusão do ensino de tais estratégias no ensino médio pelo método de integração curricular a fim de promover a autorregulação e o desenvolvimento de alunos mais autônomos, estratégicos e motivados.

Palavras-chave: Aprendizagem escolar, Estratégias de aprendizagem, Intervenção. 


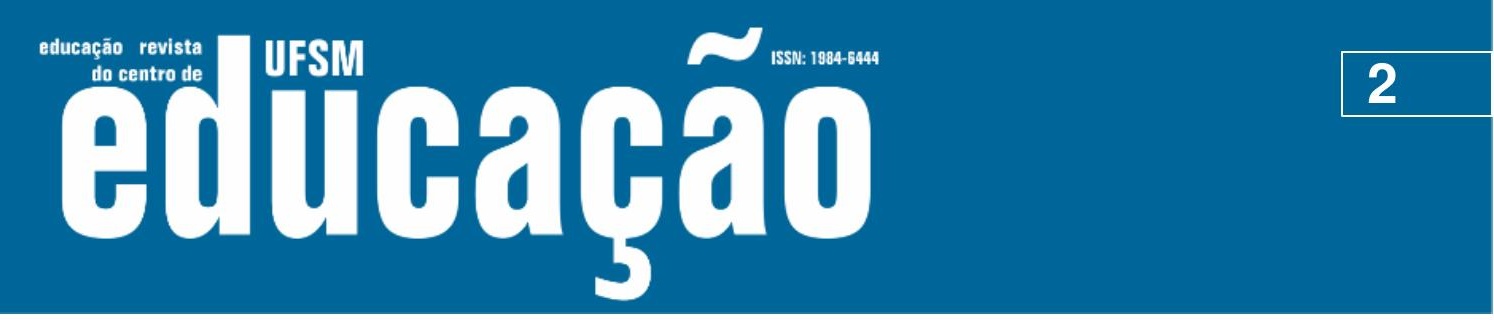

ISSN: 1984-6444 | http://dx.doi.org/10.5902/1984644438552

\begin{abstract}
This work reports an experience of an intervention by curricular integration about the teaching of learning strategies, envolving 26 students studying in the discipline of Biology in $3^{\text {rd }}$ year of High School. This Intervention is caractherized as a method in which the professor may insert the teaching of learning strategies with the content of its discipline, allied to the curricular structure. With duration of one school semester, the intervention process comprehended 36 class-hours, disposed in 13 interventive sessions organized according to the content to be ministered. Priority was given to the teaching of cognitive learning strategies due to results obtained after the application of a scale in learning strategies. After the experiment was carried out, there was a positive change in the behavior of the students in relation to the learning activities and it was verified the importance of the content domain and the knowledge inherent to the learning strategies and the possibility of including the teaching of such strategies in teaching through the method of curricular integration in order to promote self-regulation and the development of more autonomous, strategic and motivated students.
\end{abstract}

Key-words: School Learning, Learning Strategies, Intervention.

\title{
RESUMEN
}

Este trabajo relata la experiencia de una intervención por integración curricular, realizada por medio de la enseñanza de estrategias de aprendizaje, involucrando a 26 alumnos que cursaban la disciplina de Biología en el $3^{\circ}$ año de la Enseñanza Media. Esta intervención se caracteriza como un método en el que el profesor puede insertar la enseñanza de estrategias de aprendizaje junto al contenido de su disciplina, aliada a la estructura curricular. Con la duración de un semestre lectivo, el proceso de intervención comprendió 36 horas / clases dispuestas en 13 sesiones interventivas, organizadas de acuerdo con el contenido a ser dictado. Se priorizó la enseñanza de estrategias de aprendizaje cognitivas debido a los resultados obtenidos tras la aplicación de una escala en estrategias de aprendizaje. Después de la realización de la experiencia, se observó un cambio positivo en el comportamiento de los alumnos frente a las actividades de aprendizaje y se constató la importancia del dominio de los contenidos y de los saberes inherentes a las estrategias de aprendizaje y la posibilidad de inclusión de la enseñanza de tales estrategias en la enseñanza medio por el método de integración curricular a fin de promover la autorregulación y el desarrollo de alumnos más autónomos, estratégicos y motivados.

Palavras clave: Aprendizaje escolar, Estrategias de aprendizaje, Intervención.

\section{Introdução}

A Psicologia Cognitiva se propõe a estudar como as pessoas são capazes de aprender, lembrar e pensar sobre determinadas situações da vida. No contexto da 


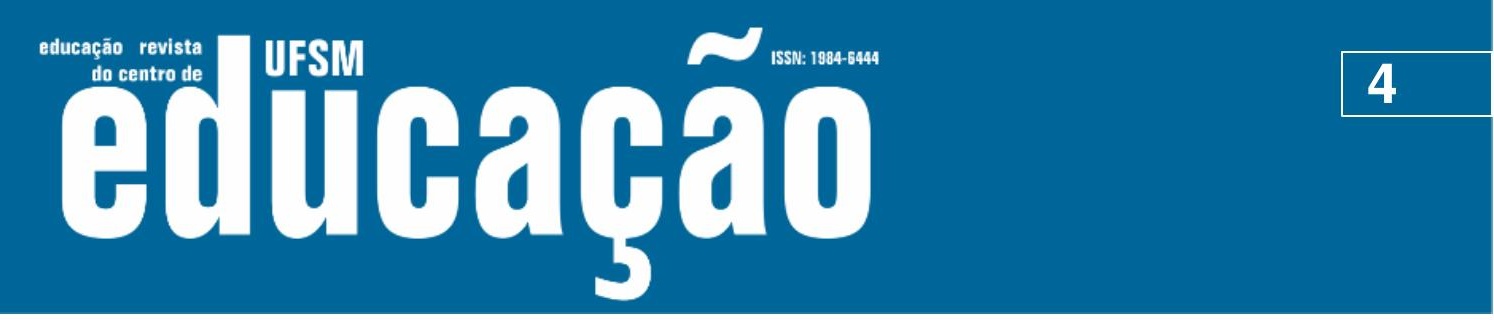

ISSN: 1984-6444 | http://dx.doi.org/10.5902/1984644438552

Além disso, Prates, Lima e Ciasca (2016), correlacionam o uso das estratégias de aprendizagem a um melhor desempenho escolar dos estudantes em conteúdos específicos como aritmética e leitura.

Considerando que a aprendizagem escolar encontra-se fortemente vinculada ao domínio dos métodos, técnicas e sobretudo das estratégias de aprendizagem, há evidências de que elas sejam inseparáveis do processo de ensinar e aprender e exigem um professor capaz de combinar o ensino de conteúdos com as técnicas, os procedimentos e as estratégias, no conjunto de suas atividades diárias (VEIGASIMÃO, 2013).

São encontradas distintas classificações para as estratégias de aprendizagem (WEINSTEIN; MAYER, 1985; ZIMMERMAN; MARTINEZ-PONS, 1986; DEMBO, 1994). No estudo aqui relatado, foi considerada a proposta de Dembo (1994), que classifica as estratégias de aprendizagem em cognitivas e metacognitivas, cuja classificação também foi adotada pela Escala de Avaliação das Estratégias de Aprendizagem para o Ensino Fundamental (EAVAP-EF), proposta e validada por Oliveira, Boruchovitch e Santos, (2010). Esta Escala é composta por três fatores, conforme segue: Fator 1 - estratégias de aprendizagem cognitivas que se referem à organização, elaboração e integração da informação a ser aprendida; Fator 2 estratégias de aprendizagem metacognitivas, voltadas ao planejamento, monitoramento, regulação do próprio pensamento e Fator 3 - ausência de estratégias metacognitivas disfuncionais, que indicam atitudes prejudiciais ou ineficazes ao processo de aprendizagem.

Os resultados positivos alcançados pelos programas de intervenção em estratégias de aprendizagem podem ser observados nos mais variados níveis escolares (WOLTERS, 2010). Estes programas podem ser classificados de acordo com a modalidade, o formato, o conteúdo e o tempo de duração (HOFER; YU; PINTRICH, 1998; ZIMMERMAN; TSIKALAS, 2005). Segundo estes autores, em relação à modalidade, os programas de intervenção podem acontecer de modo presencial, virtual ou misto. O formato pode ser por integração curricular, quando acontece dentro do contexto de uma disciplina específica do curso, ou por 


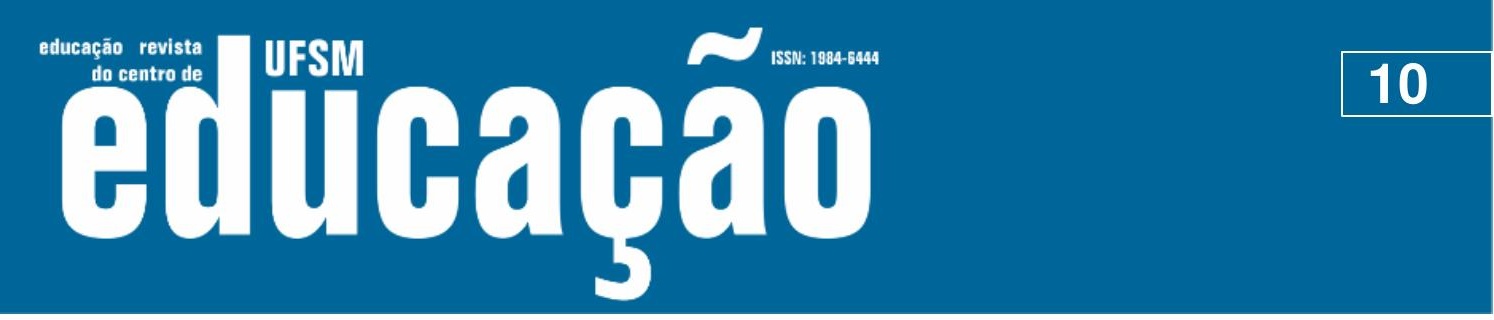

ISSN: 1984-6444 | http://dx.doi.org/10.5902/1984644438552

significativo na capacidade de conexões realizadas entre os conteúdos nas disciplinas. Para Erasmus (2013), a elaboração de mapas conceituais ajuda os alunos a se envolverem com o assunto de maneira ativa, em vez de apenas ouvir uma palestra, aula expositiva ou apresentação em PowerPoint. Ao final da aula, como tarefa, os alunos foram orientados a 'pesquisar em bibliografia alternativa' sobre a $1^{\text {a }}$ Lei de Mendel e trazer um resumo para a próxima aula. Por estarem sempre regulados por notas, 15 (57,69\%) alunos perguntaram quanto valeria a atividade e o professor apenas informou que daria nota, sem especificar o valor.

Sessão 3: Constituída por quatro aulas. No início da sessão, todos os grupos entregaram os mapas conceituais e o professor questionou sobre o conteúdo que haviam pesquisado em casa, direcionando a aula de modo a contemplar todos os assuntos relativos à $1^{\text {a }}$ Lei de Mendel. Após os relatos sobre os conteúdos pesquisados, iniciou-se uma aula expositiva e o professor indicou que eles deveriam 'anotar as informações que julgassem importantes'. No transcorrer da aula, notou-se que 23 deles $(88,46 \%)$ anotavam tudo o que o professor falava e até pediam para que o conteúdo explicado fosse repetido. Depois, foram instruídos a 'elaborar uma pergunta e sua resposta' a respeito do conteúdo aprendido.

Segundo Kipper e Rüütmann (2010), as sessões de perguntas nas salas de aula devem ser experiências construtivas e alegres, nas quais as opiniões dos alunos são respeitadas, seus interesses estimulados e suas mentes desafiadas. Se o ensino e a aprendizagem devem ser autênticos, os professores precisam ensinar seus alunos a pensar. Os autores consideram o questionamento uma das estratégias poderosas para o ensino do pensamento crítico e do entendimento profundo do conteúdo.

Segundo Tofade, Elsner e Haines (2013), a elaboração de perguntas e respostas permite que os alunos analisem, avaliem e criem estimulando sua criatividade e sua interação com o conteúdo, provocando maior atenção à metacognição e às respostas pessoais por meio de perguntas efetivas que podem levar a insights profundos. A clareza, o sequenciamento e o nível de dificuldade influenciam as percepções dos alunos, a motivação e o desempenho para melhorar a qualidade do ensino. 


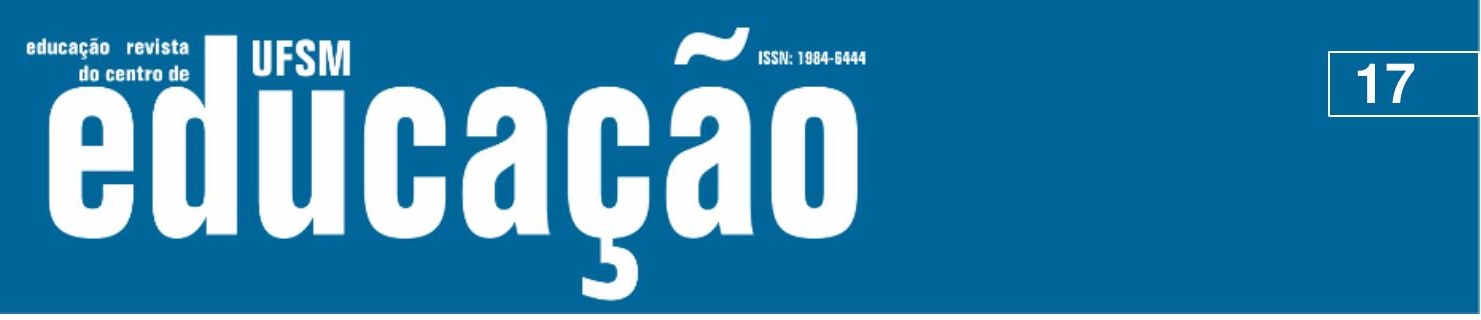

ISSN: 1984-6444 | http://dx.doi.org/10.5902/1984644438552

Ante tal comportamento, o professor indagou a eles: "- O que foi? Nunca receberam feedbacks dos seus trabalhos?" Um dos alunos respondeu: “- Não professor, a gente só recebe os trabalhos com certo ou errado". Os feedbacks dados aos alunos apresentavam frases como "Parabéns, continue, você fez um ótimo trabalho!" ou "Vejo que você está aprendendo muito em Biologia, estou gostando de ver!". A importância dos feedbacks para os constructos motivacionais tem sido indicada por vários autores, dentre eles Bzuneck e Guimarães (2010) e Maieski, Oliveira e Bzuneck (2013). Iniciouse, então, um 'debate' sobre os conceitos, significado, função e importância do sistema $A B O$. Diante da dificuldade dos alunos com o conteúdo de aglutinação, o professor apresentou no quadro um esquema com explicações sobre aglutininas e aglutinogênios. Na segunda aula, os alunos foram estimulados a 'elaborar uma lista de ideias' sobre os conteúdos aprendidos. Do total de alunos, 18 (69,23\%) deles realizaram o solicitado além de irem 'anotando as informações que julgavam importantes' no decorrer das explicações do professor, sem que houvesse sido solicitado previamente, número maior em relação à Sessão 6 ( $n=16 / 61,53 \%)$. Na sequência, todos foram estimulados a 'elaborar perguntas e respostas' sobre o conteúdo, em grupos, para 'discutirem' a melhor forma de elaborar a atividade.

É importante salientar que nesta fase da intervenção, nenhum aluno reclamava por ter que desenvolver atividades em que era requerido o uso das estratégias de aprendizagem, comportamento que era frequentemente observado no início da intervenção. De acordo com Wegner, Minnaert e Strenhkke (2013), na medida em que as estratégias são ensinadas intencionalmente e aplicadas conscientemente pelos indivíduos, aos poucos são incorporadas aos comportamentos e reflexões do aprendiz e automatizadas no processo de autorregulação, o que implica em uma normalização sobre o uso de estratégias, o que pode justificar o comportamento dos participantes da presente pesquisa em deixar de reclamar em ter que usar as estratégias de aprendizagem, ao longo da intervenção. No fim da aula, o professor solicitou uma pesquisa sobre $2^{\underline{a}}$ Lei de Mendel e a elaboração de um quadro comparativo entre a $1^{\text {a }}$ e a $2^{\text {a }}$ Lei.

Sessão 10: Constituída por quatro aulas sobre a $2^{\underline{a}}$ Lei de Mendel. O professor pediu a elaboração de um 'resumo sem consulta ao material' sobre todos os temas de 


\section{Autharẫ}

ISSN: 1984-6444 | http://dx.doi.org/10.5902/1984644438552

$\mathrm{Na}$ aula três, o professor pediu para que 'fizessem duas listas', sendo uma sobre o que entenderam e outra sobre o que não entenderam a respeito do assunto. A partir das dúvidas que emergiram nesse processo, sempre o professor perguntava se alguém sabia a resposta. Caso não houvesse manifestação, o professor intervinha respondendo. Para finalizar, foi solicitado que os alunos 'elaborassem esquemas' sobre a formação de gametas recombinantes ou crossing-over para apresentar se organizando em grupos de forma que todos contribuíssem para a produção e todos os 26 alunos (100\%), participaram da atividade.

$\mathrm{Na}$ aula quatro, os alunos elaboraram um quadro em cartolina 'elencando as diferenças' entre herança do sexo na espécie humana, herança ligada ao sexo, herança holândrica, herança influenciada pelo sexo e herança limitada ao sexo. No fim da aula, o professor pediu uma 'pesquisa' individual sobre como elaborar portfólio e, em grupos, cada um pesquisasse um conteúdo a respeito de: síntese de proteínas; transcrição; tradução; mutações no material genético; biotecnologia e engenharia genética: organismos geneticamente modificados (OGMs), projeto genoma, terapia gênica e clonagem.

Sessão 12: Composta por quatro aulas sobre genética molecular. No início da aula, o professor tirou algumas dúvidas em relação à elaboração do portfólio. Para trabalhar os conteúdos propostos, foi indicado aos alunos que 'escolhessem' uma das estratégias de aprendizagem trabalhadas anteriormente, para cada um dos temas apresentados e que 'elaborassem o portfólio' em grupos. No fim da segunda aula, pediu que produzissem nucleotídeos em moldes de EVA em casa, para explicar síntese de proteínas, transcrição e tradução. Informou que deveriam ser formados apenas três grandes grupos.

Na terceira aula, cada um dos três grupos 'explicaram os conteúdos' no quadro, colando os moldes de EVA e, enquanto um grupo apresentava, os que assistiam à apresentação 'faziam as perguntas que elaboraram em casa'. Os alunos respondiam aos questionamentos demonstrando com o material produzido.

$\mathrm{Na}$ quarta aula da sessão, foi organizada uma 'mesa redonda' sobre biotecnologia e engenharia genética. Para o desenvolvimento da atividade, 0 professor trouxe reportagens sobre o assunto para que os alunos 'discutissem', sendo 


\section{Aillbapẫ}

ISSN: 1984-6444 | http://dx.doi.org/10.5902/1984644438552

elaboração de comparação entre espécies (FILHO et al., 2015), e apresentam resultados positivos na aprendizagem e desempenho acadêmico dos alunos que aprenderam o conteúdo pelos referidos métodos.

Iniciativas como esta são importantes haja vista que Filho et al. (2015) demonstram que em relação as estratégias de ensino, os professores optam, em grande maioria, pela aula expositiva, sem propor diferentes estratégias ou recursos. Além disso, os autores verificam erros conceituais sobre o conteúdo nas respostas dos professores e essa não familiaridade com o conteúdo pode ser considerada um obstáculo para que os professores elaborem estratégias de ensino e utilizem recursos com potenciais para ensino de evolução.

Por fim, os registros revelaram que sete $(26,92 \%)$ estudantes selecionaram estratégias sobre aprendizagem cognitivas de resumir, seis $(23,07 \%)$ elaboraram uma lista de ideias sobre o conteúdo, cinco $(19,23 \%)$ produziram perguntas e respostas sobre o conteúdo, três $(11,53 \%)$ colocaram as informações que julgavam importantes sobre o assunto, três $(11,53 \%)$ grifaram partes importantes do material pesquisado, um $(3,84 \%)$ fez um mapa conceitual e outro $(3,84 \%)$ estabeleceu comparações, associações, complementaridade e divergência entre os assuntos pesquisados no formato de tabela.

\section{Considerações finais}

Intervenções em estratégias de aprendizagem pelo método de integração curricular não são simples e exigem promover no aluno a autorregulação a fim de se tornar ativo no processo de aprendizagem, como já descrito por Santos e Alliprandini (2017) e Ganda e Boruchovitch, (2018). Porém promover a autorregulação exige que o professor seja um bom aprendiz e conheça seus próprios processos cognitivos e metacognitivos, tornando-se, portanto, um sujeito ativo no próprio processo de aprendizagem, já que o profissional é bastante requisitado durante o processo de ensino e a promoção no uso de estratégias de aprendizagem (BORUCHOVITCH, 2014). 


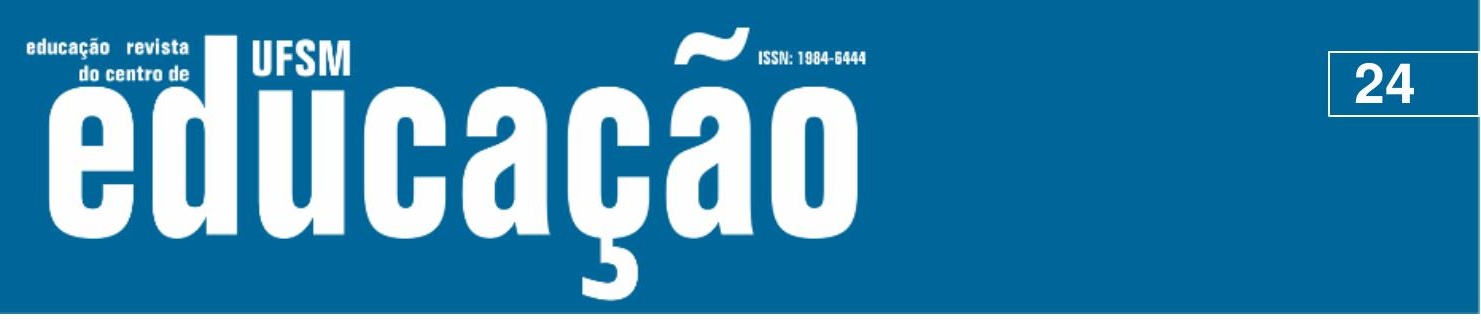

ISSN: 1984-6444 | http://dx.doi.org/10.5902/1984644438552

buscar ajuda, tirar dúvidas, fazer mapas conceituais, elaborar lista de ideias, explicar em voz alta os conteúdos aprendidos, pesquisar em bibliografia alternativa, reler o conteúdo, e estabelecer comparações, associações, complementaridade e divergência entre os assuntos pesquisados - foram trabalhadas durante as quatro aulas da Sessão 1, elas continuaram a ser incessantemente utilizadas e destacada a sua importância, visando o envolvimento dos alunos, nas sessões subsequentes. Como já descrito por Boruchovitch (2010), não basta conhecer um repertório de estratégias de aprendizagem, os alunos precisam ser ensinados a como e quando utilizá-las e de maneira eficaz.

Ao longo das sessões de intervenção, os alunos passaram a utilizar mais as estratégias de aprendizagem de 'pedir ajuda', o que pode ser atribuído ao fato de que passaram a se perceber mais no processo de aprendizagem, inclusive ao constatarem quando não estavam conseguindo entender determinado assunto. Como exemplo disso, na Sessão 3 de intervenção os alunos 'pediram ajuda ao professor' para 'elaborar resumos' e 'compreender o conteúdo' e, na Sessão 7, 'pediram ajuda' a uma professora da disciplina de Português, para aprenderem a fazer redação. De forma solícita, a professora atendeu à solicitação e se disponibilizou em horário oposto para auxiliá-los.

Observou-se também uma mudança de comportamento em relação às estratégias de 'listar ideias' e 'anotar informações que julgavam importantes', na Sessão 6, 16 alunos (61,53\%) desenvolveram estas atividades no decorrer das explicações do professor sem que houvesse solicitação prévia e, na Sessão 9, os dados demonstram aumento para 18 (69,23\%). É importante ainda salientar a importância dos feedbacks, descritos na Sessão 9, em que os próprios estudantes demonstram satisfação com os comentários aplicados sobre o resultado de suas atividades. Além disso, o comportamento inicial dos alunos, quando solicitados a escrever sem consultar nenhum material, modificou-se, visto que, inicialmente, ficavam preocupados, olhando a atividade do colega, mas, depois de algum tempo, passaram a escrever o que entendiam do assunto, sem copiar.

Esta mudança foi percebida por outros professores, que perguntavam o que o professor de Biologia estava fazendo para os alunos estarem sempre preocupados 


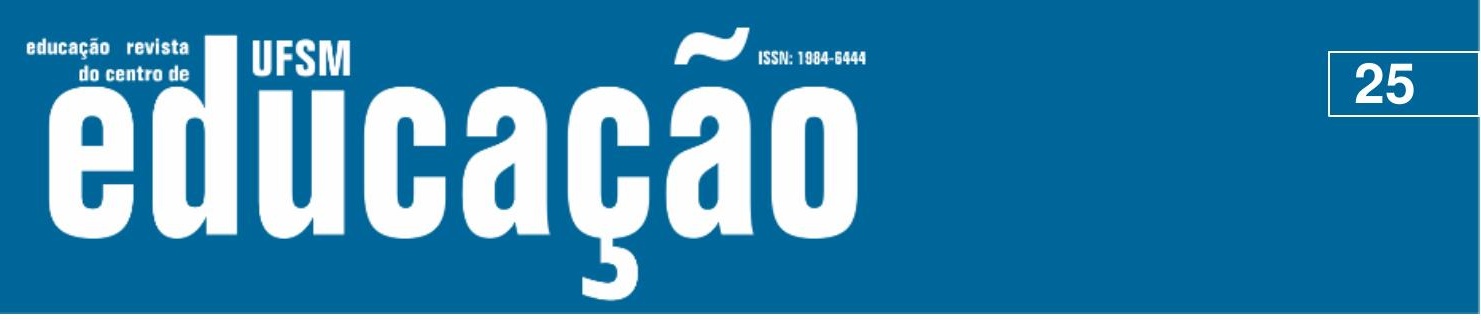

ISSN: 1984-6444 | http://dx.doi.org/10.5902/1984644438552

em realizar as tarefas da disciplina. O fato deles terem solicitado ajuda da professora de Português para elaborar redações é uma evidência marcante da mudança de comportamento em função da intervenção, uma vez que esta prática não havia acontecido antes.

Ficou evidenciado que a realização de pesquisa sobre o conteúdo antes de ocorrer à aula facilita a ministração, porque o aluno já detém um conhecimento, ainda que inicial e precário, que possibilita o diálogo em sala de aula. A partir dela, cabe ao professor organizar os conceitos, esclarecer dúvidas e, pelo método de questionamento, contribuir para que o aluno reflita sobre o conteúdo, utilizando as diversas estratégias disponíveis, promovendo assim o uso da metacognição.

A intervenção por intermédio de estratégias de aprendizagem requer que o professor, neste processo, domine não só o conteúdo, como tenha domínio sobre as estratégias de aprendizagem. Pressupõe o desencadeamento de um processo que precisa adequar a estratégia ao conteúdo a ser desenvolvido durante a aula, correlação que exige bastante esforço cognitivo e metacognitivo do profissional.

Embora não tenha sido o objetivo da intervenção, é importante destacar que, em decorrência do ensino de estratégias o docente percebeu certa facilidade em relação ao cumprimento do currículo acadêmico e do planejamento ao longo do ano letivo, além disso, os alunos melhoraram consideravelmente seu desempenho acadêmico, pois no início da intervenção, dez alunos (40\%) tinham nota abaixo da média na disciplina e, no último semestre, apenas um aluno $(3,7 \%)$ tirou nota abaixo da média.

Foi notório ainda um aumento na interação entre os alunos e dos alunos com o professor por meio do ensino de estratégias por integração curricular, provavelmente pelo fato de que o uso da estratégia de pedir ajuda junto aos colegas e ao professor, 'socializar perguntas e respostas', 'elaborar esquemas em grupo', dentre outras atividades propostas exigiam essa interação. Além disso, os alunos demonstraram um maior protagonismo no processo de ensino, maior autonomia e autorregulação da aprendizagem ao se perceberem integrados ao processo ensino aprendizagem e demonstrarem, mediante participação, questionamentos realizados e reflexões propostas. 


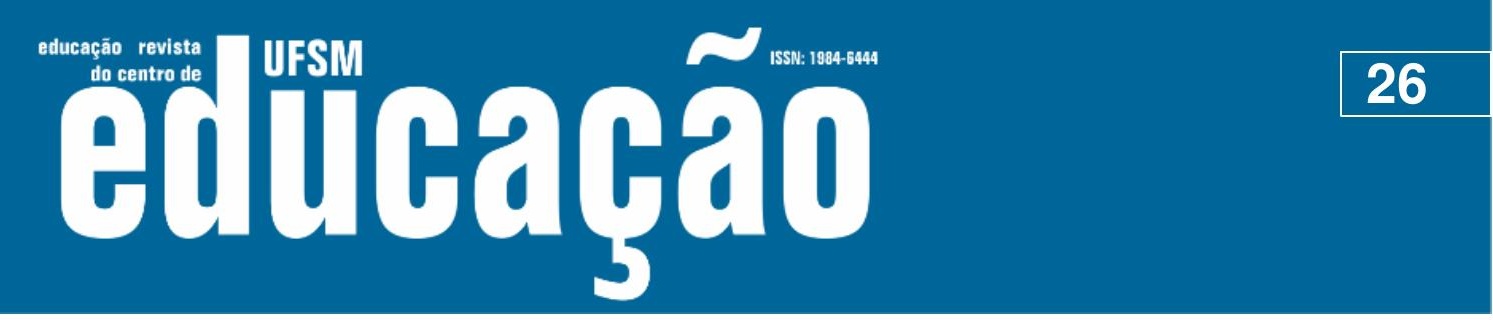

ISSN: 1984-6444 | http://dx.doi.org/10.5902/1984644438552

Espera-se, por meio da apresentação deste trabalho, ter contribuído para elucidar um processo de intervenção quanto ao ensino das estratégias de aprendizagem por integração curricular. Sugere-se que mais pesquisas e experiências sejam realizadas neste nível educacional relacionadas ao uso e promoção das estratégias de aprendizagem por alunos e professores. Considerando os efeitos positivos da intervenção realizada, conforme descrito neste relato de experiência pedagógica, este estudo fortalece as pesquisas realizadas na área sobre a importância do aprender a aprender e a necessidade de formação de professores voltada para o ensino das estratégias de aprendizagem como promotora da autorregulação da aprendizagem dos alunos.

\section{Referências}

ALVES, Marcus Vinicius Costa; MODESTO, João Gabriel; LIMA-ROSSETTI, Deborah; LANINI, Juliana; BUENO, Orlando Francisco Amodeo. As dimensões da Carga Cognitiva e o Esforço Mental. Revista Brasileira de Psicologia, v. 04, n.01, 2017.

ANDRZEJEWSKI, Carey E.; DAVIS, Heather A.; BRUENING, Paige Shalter; POIRIER, Ryan R. Can a self-regulated strategy intervention close the achievement gap? Exploring a classroom-based intervention in 9th grade earth science. Learning and Individividual Differences, Alburne, v. 49, p. 85-99, mai./2016.

BORTOLETTO, Denise; BORUCHOVITCH, Evely. Learning Strategies and Emotional Regulation of Pedagogy Students. Paidéia (Ribeirão Preto), Ribeirão Preto, v. 23, n. 55, p. 235-242, ago./2013.

BORUCHOVITCH, Evely. A auto-regulação da aprendizagem e a escolarização inicial. In: BORUCHOVITCH, Evely; BZUNECK, José Aloyseo (Orgs.). Aprendizagem: Processos Psicológicos e o Contexto Social na Escola. $2^{\underline{a}}$ ed. Petrópolis: Editora Vozes, 2010. p. 55-88.

BORUCHOVITCH, Evely. Autorregulação da aprendizagem: contribuições da psicologia educacional para a formação de professores. Psicologia Escolar e Educacional, São Paulo, v. 18, n. 3, p. 401-409. 2014.

BZUNECK, José Aloyseo. Como motivar os alunos: sugestões e práticas. In: BORUCHOVITCH, Evely; BZUNECK, José Aloyseo; GUIMARÃES, Sueli Édi Rufini (Orgs.). Motivação para aprender: aplicações no contexto educativo. $2^{\underline{a}}$ ed. Petrópolis: Editora Vozes, 2010. p. 13- 42. 


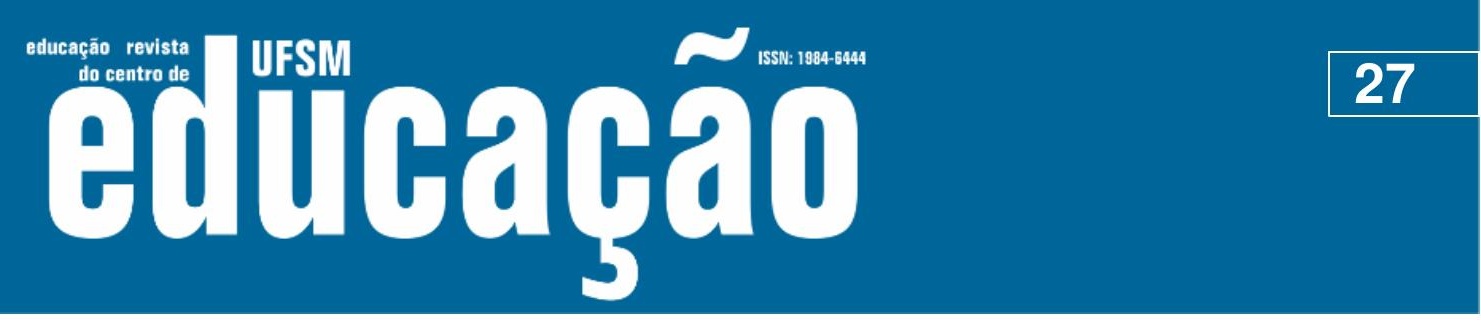

ISSN: 1984-6444 | http://dx.doi.org/10.5902/1984644438552

BZUNECK; José Aloyseo; GUIMARÃES, Suely Édi Rufini. A promoção da autonomia como estratégia motivacional na escola: uma análise teórica e empírica. In: BORUCHOVITCH, Evely; BZUNECK, José Aloyseo; GUIMARÃES, Suely Édi Rufini (Orgs.). Motivação para aprender: aplicações no contexto educativo. $2^{\underline{a}}$ ed. Petrópolis: Editora Vozes, 2010. p. 43- 70.

ÇETINGÖZ, Duygu. University students' learning processes of note-taking strategies. Procedia Social and Behavioral Sciences, v.2, p.4098-4108, 2010.

DEMBO, Myron. H. Applying educational psychology. $5^{\text {a }}$ ed. White Plains, NY: Longman Publishing Group. 1994.

DI CARLO, Sérgio. Understanding Cognitive Language Learning Strategies International. Journal of Applied Linguistics \& English Literature, v.6, n.2, p.114126, mar./2017.

ERASMUS, Charlene J. Concept Mapping as a Strategy to Enhance Learning and Engage Students in the Classroom. Journal of Family and Consumer Sciences Education, v.31, n.1, p.27-35, 2013.

EYSENCK, Michael. W. Manual de Psicologia Cognitiva. Tradução de Luís Fernando Marques Dorvillé e Sandra Maria Mallmann da Rosa. 7. ed. Porto Alegre: Artmed. 2017.

FILHO, Francisco Brenzam; COLMAN, Diego Armando Lopes; VAN DAL, Paula da Costa; ANDRADE, Mariana A. Bologna Soares de. Evolução Biológica e Estratégias de Ensino de Professores de Biologia. Anais do EDUCERE XII Congresso Nacional de Educação; PUCPR, 2015.

GANDA, Danielle Ribeiro. A autorregulação da aprendizagem de alunos em curso de formação de professores: Um programa de intervenção. 2016. 143 f. Tese (Doutorado em Educação) - Universidade Estadual de Campinas, Campinas, 2016.

GANDA, Danielle Ribeiro; BORUCHOVITCH, Evely. Promoting Self-regulated Learning of Brazilian Preservice Student Teachers: Results of na Intervention Program. Frontiers in Education, Madrid, v. 3, p. 1-12, fev./2018.

GRAU, Valeska; WHITEBREAD, David. Self and social regulation of learning during collaborative activities in the classroom: The interplay of individual and group cognition.

Learning and Instruction, v.22, p.401-12, 2012.

HADWIN, Allyson Fiona. F.; JÄRVELÄ, Sanna.; MILLER, Mariel. Self-regulated, coregulated, and socially shared regulation of learning. In: ZIMMERMAN, Barry J.; SCHUNK, D.H. (eds). Handbook of Self-Regulation of Learning and Performance. Routledge, New York, 2011. p. 65-84.

HAFIZ, Moustafa; KADIR, Ozakgul; FATRA, Maifalinda. Concept mapping learning strategy to enhance students' mathematical connection Ability. AIP Conference Proceedings, v.1848, 2017. 




ISSN: 1984-6444 | http://dx.doi.org/10.5902/1984644438552

WEGNER, Claas; MINNAERT, Lea; STREHLKE, Friederike. The Importance of Learning Strategies and How the Project "Kolumbus-Kids" Promotes Them Successfully. European Journal of Science and Mathematics Education, v. 1 n. 3 p. 137-143, 2013.

WEINSTEIN, Claire ; MAYER, Richard E. The teaching of learning strategies. In: Merlin WITTROCK (Orgs.). Handbook of research on teaching. New York: Macmillan. 1985. p. 315-327.

WOLTERS, Christopher. Self-Regulated Learning and the 21st Century Competences. Houston: Department of Educational Psychology. University of Houston, p. 1-27. 2010.

WOLTERS, Christopher; BENZON, Maria. Assessing and predicting college students' use of strategies for the self-regulation of motivation. Journal of Experimental Education, v.81, n.2 p.199-221, 2013.

YABER, Renata Lopes da Silva; BARROS, Marcelo Diniz Monteiro de. Estudando a Evolução Biológica por meio de Histórias em Quadrinhos. Trilhas Pedagógicas, v.7, n.7, p. 103-122, 2017.

ZIMMERMAN, Barry J. Academic studying and the development of personal skill: a self-regulated perspective. Educational Psychologist, v. 33, n. 2/3, p. 73-86. 1998a.

ZIMMERMAN, Barry J. TSIKALAS, Kallen E. Can Computer-Based Learning Environments (CBLEs) Be Used as Self-Regulatory Tools to Enhance Learning?. Educational Psychologist, v. 40, n. 4, p. 267-271. 2005.

ZIMMERMAN, Barry, J. Developing Self-Fulfilling Cycles of Academic Regulation: An analysis of exemplary instructional models. In SCHUNK, D. H; ZIMMERMAN, B. J. (Orgs.). Self-regulated learning: from teaching to self-reflective practice. Nova York: The Guilford Press. pp. 1-19. 1998b.

ZIMMERMAN, Barry, J.; MARTINEZ-PONS, Manuel. Development of a Structured Interview for Assessing Student Use of Self-Regulated Learning Strategies. American Educational Research Journal, v. 23, n. 4, p. 614-628. 1986.

ZIMMERMAN, Barry. J. From cognitive modeling to self-regulation: a social cognitive career path. Educational Psychology, v.48, p.135-147, 2013.

ZIMMERMAN, Barry. J.; MOYLAN, Adam, R. Self-regulation: Where metacognition and motivation intersect. In: HACKER, Douglas J.; DUNLOSKY, John.; GRAESSER, Arthur C. (Eds.), The educational psychology series. Handbook of metacognition in education. Routledge/Taylor \& Francis Group. 2009. p. 299-315. 


\section{Try

ISSN: 1984-6444 | http://dx.doi.org/10.5902/1984644438552

\section{Correspondência}

Deivid Alex dos Santos - Universidade Estadual de Londrina - Rodovia Celso Garcia Cid, 445, Km 380 - Campus Universitário, CEP 86057-970, Londrina, Paraná, Brasil.

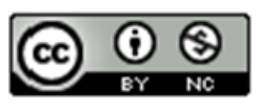

This work is licensed under a Creative Commons Attribution-NonCommercial 4.0 International (CC BY-NC 4.0) 